\title{
Ações de startups e empresas brasileiras no combate à pandemia da COVID-19
}

\section{Actions of Brazilian startups and companies to combat the pandemic COVID-19}

\author{
Juliana Martins Machado ${ }^{\mathrm{a}^{*}}$ \\ Aline Emily de Oliveira ${ }^{a^{*}}$ \\ Jonatas Oliveira da Silva ${ }^{a^{*}}$ \\ Michelli dos Santos ${ }^{a^{*}}$ \\ Mariana Ferraz Chaves Francisco ${ }^{a}$ \\ Ana Luísa Faria Muniz ${ }^{\mathrm{a}}$ \\ André Vinícius Fernandes Ferreira ${ }^{a}$ \\ Laís Moreira Nogueira ${ }^{a}$ \\ Cristiane Bittencourt Barroso Toledo ${ }^{\mathrm{b}}$ \\ Rosângela da Silva Lomeo ${ }^{c}$ \\ Rodolfo Cordeiro Giunchetti ${ }^{\mathrm{d}}$ \\ Mariana Campos da Paz ${ }^{\mathrm{e}}$ \\ Alexsandro Sobreira Galdino ${ }^{\text {a\# }}$.
}

RESUMO

Introdução: A COVID-19 é uma doença de interesse mundial. Diante disso, há um esforço globalizado no desenvolvimento de produtos/soluções que possam apoiar a sociedade neste momento. Objetivo: O objetivo desse trabalho foi relatar as ações e iniciativas de algumas startups brasileiras, destinadas ao combate da COVID-19. Método: Para isso, uma pesquisa assistemática em plataformas e sites de notícias foi realizada, entre 1 de março e 5 de junho de 2020, e 71 iniciativas foram identificadas em diferentes categorias: antipropagação da COVID-19, inteligência artificial, sistemas de gestão em saúde, coleta/monitoramento de informações, artigos e exames hospitalares, diagnóstico e telemedicina. Conclusão: Por meio deste estudo, foi possível evidenciar o desenvolvimento de tecnologias nacionais para solucionar problemas como falta de equipamentos de proteção individual e hospitalares, triagem e monitoramento da população, além de melhoria do acesso às informações sobre cuidados, prevenção e aos serviços de saúde em meio a pandemia. No entanto, algumas destas iniciativas ainda precisam de incentivos para chegar ao mercado.

\section{PALAVRAS-CHAVE}

COVID-19; Inovação; Empreendedorismo; Startups.

\footnotetext{
a Laboratório de Biotecnologia de Microrganismos, Universidade Federal de São João Del-Rei, 35501-296, Divinópolis, MG, Brasil.

${ }^{\mathrm{b}}$ Fundação Biominas, Biominas Brasil, 31035536, Belo Horizonte, MG, Brasil.

${ }^{c}$ RLomeo Marcas \& Patentes, 31160-130, Belo Horizonte, MG, Brasil.

${ }^{d}$ Laboratório de Biologia das Interações Celulares, Universidade Federal de Minas Gerais, Belo Horizonte, MG, Brasil.

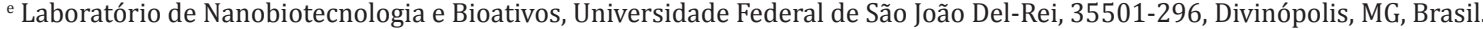

* Os autores contribuíram de forma equivalente neste trabalho.

\# Autor Correspondente: Alexsandro Sobreira Galdino, Laboratório de Biotecnologia de Microrganismos, Universidade Federal de São João Del-Rei, MG, Divinópolis 355901-296. E-mail: asgaldino@ufsj.edu.br ; asgaldino@gmail.com

Conflitos de interesse: "não há conflito de interesse".
} 


\begin{abstract}
Introduction: COVID-19 is a disease of international interest. Therefore, there is a global effort to develop products / solutions that can support society at this time. Objective: The purpose of this article is to report the actions and initiatives of some Brazilian startups, aimed at combating COVID-19 and mitigating its impacts. Method: Therefore, an unsystematic research was carried out on news platforms and websites, between March 1 and June 5, 2020, and 71 initiatives were identified in different categories: anti-propagation of COVID-19, artificial intelligence, health management systems, collection and monitoring of information, articles and hospital exams, diagnosis and telemedicine. Conclusion: Through this study, it was possible to evidence the development of national technologies to solve problems, such as lack of personal and hospital protective equipment, to screen and monitor the population, in addition to improving access to information on care, prevention and health services amid the pandemic. However, some of these initiatives still need incentives to reach the market.
\end{abstract}

\title{
KEYWORDS
}

COVID-19; Innovation; Entrepreneurship; Startups. 


\section{INTRODUÇÃO}

O SARS-CoV-2 se espalhou rapidamente pelo mundo e, em março de 2020, foi classificado como uma pandemia pela Organização Mundial de Saúde - OMS. Atualmente, o vírus está presente em 216 países/territórios,sendo mais de 27.205.275 casos confirmados e 890.392 mortes até 8 de setembro de 2020. As regiões mais afetadas pela pandemia são as Américas, sudoeste da Ásia e a Europa. Nas Américas, os países mais afetados são os Estados Unidos, com 6.222.974 casos confirmados e 188.172 mortes, e o Brasil, com 4.137.521 casos e 126.650 mortes (WHO, 2020a,b)..

Em janeiro de 2020, a OMS classificou a doença como uma emergência de saúde pública de interesse internacional (SOHRABI et al., 2020). Por esta razão, diversos países têm concentrado esforços de forma global para conter o avanço da COVID-19 e mitigar o surto, visando à redução da transmissão e à proteção de populações suscetíveis (idosos, crianças, profissionais de saúde e portadores de comorbidades) (GORBALENYA et al., 2020).

O impacto global da pandemia da COVID-19 é um motivo de grande preocupação, pois, além de afetar o setor da saúde pública, a doença é responsável por impactos psicossociais negativos na população, como estresse, ansiedade, problemas mentais, e ainda por alterações na economia mundial (HALEEM; JAVAID; VAISHYA, 2020).

Diferentes setores da economia têm sido comprometidos pela doença, como a interrupção da cadeia de suprimentos, a desaceleração do crescimento, perdas em negócios nacionais e internacionais e a demissão de funcionários (NICOLA et al., 2020). Além disso, a pandemia tem afetado principalmente os mais pobres, que não tem acesso aos serviços de saúde e se tornam mais vulneráveis (AHMED et al., 2020). Diante deste cenário, em que cresce a cada dia o número de infectados/mortos, torna-se essencial a pesquisa e o desenvolvimento de possíveis soluções que possam dar suporte à sociedade no enfrentamento desta pandemia.

Desde o início da pandemia, diversas iniciativas têm tentado mapear projetos ou ações de empresas, startups e profissionais voltadas para a busca de soluções de prevenção e combate à COVID-19. Assim, esse artigo tem como objetivo relatar as ações e iniciativas de algumas startups brasileiras, destinadas ao combate da COVID-19 e à mitigação de seus impactos.

\section{METODOLOGIA}

Neste estudo, uma pesquisa foi realizada em sites de notícias e plataformas públicas, com acesso irrestrito na internet, que reportassem empresas ou startups que foram criadas no período da pandemia e/ou passaram a propor soluções para a COVID-19.

A pesquisa de dados foi realizada entre 01 de março e 05 junho de 2020. Dois critérios de corte foram definidos: reportar neste estudo apenas iniciativas de empresas e startups brasileiras e soluções relacionadas à pandemia da COVID-19. Uma busca assistemática foi realizada, empregando as seguintes palavras-chave e operadores booleanos: "startup e COVID-19", "startup e SARS-CoV-2", "startup e pandemia 2020".

\section{RESULTADOS E DISCUSSÃO}

Foram identificadas 88 organizações (empresas ou startups) com iniciativas para enfrentamento da COVID-19. Após o mapeamento e avaliação dos dados com base nos critérios de corte estabelecidos, foram selecionadas 71 iniciativas para análise neste artigo.

As iniciativas foram organizadas em 7 categorias, conforme pode ser observado na figura 1.

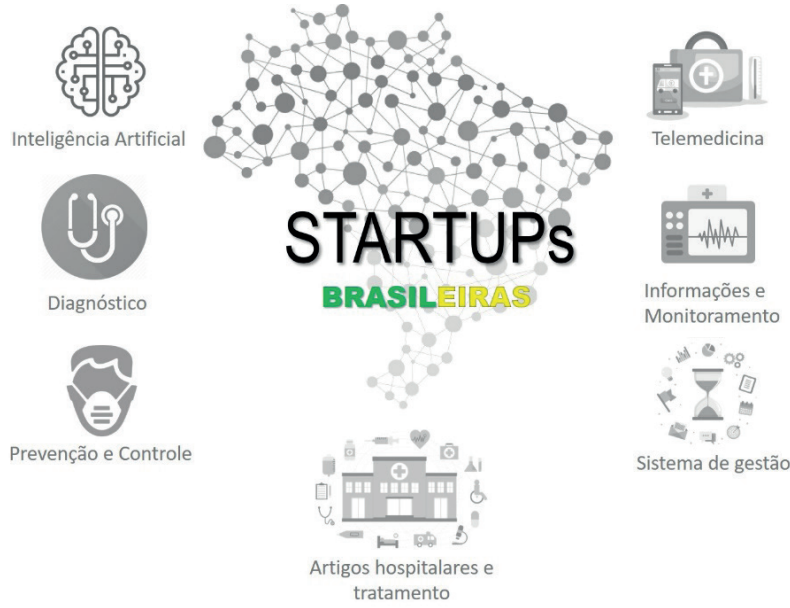

Figura 1. Ilustração de algumas categorias de iniciativas de inovação na área de saúde humana para o combate a pandemia da COVID-19 por startups brasileiras, durante o período de 01 de Março a 05 de junho de 2020. Ilustração feita por AS Galdino. Os ícones dessa ilustração foram elaborados por freepik (https://br.freepik.com/home), flaticon https://www.flaticon.com/) e teoriadigital (http://www.teoriadigital.com.br/tecnologia/brasil-lidera-inovacao-e-adocao-de-novas-tecnologias-na-america-latina/) 
Dentre estas categorias, 11 iniciativas reportaram soluções frente à prevenção e antipropagação da COVID-19, 6 iniciativas baseiam-se na Inteligência Artificial, 12 iniciativas propõem auxílio para sistemas de gestão, 9 iniciativas auxiliam na coleta de informações e monitoramento de pacientes, 4 iniciativas abordam artigos hospitalares e tratamentos, 18 iniciativas foram direcionadas para diagnóstico e 11 iniciativas se referem ao atendimento remoto (telemedicina). Um breve resumo das inovações propostas pode ser observado na tabela 1.

As empresas e startups avaliadas durante o período de coleta dos dados se concentraram em sua maioria no estado de Minas Gerais (60,56\%), seguido de São Paulo $(23,94 \%)$, Rio de Janeiro (5,63\%), Goiás (4,16\%), Santa Catarina (2,81\%), Pernambuco (1,40\%) e Rio Grande do Sul $(1,40 \%)$.

\subsection{Prevenção e antipropagação da COVID-19}

Desde o início da pandemia, uma série de medidas de contenção do novo coronavírus foram implementadas. Até o momento, nenhuma terapia antiviral específica foi aprovada para o tratamento da COVID-19 e o modo mais eficaz no combate ao SARS-CoV-2 é evitar sua propagação por ações como a higienização das mãos, o distanciamento social e a quarentena (GÜNER; HASANOGLU; AKTAS, 2020).

Um dos modos de prevenção da COVID-19 consiste no monitoramento ativo do aparecimento de sintomas em pessoas que foram expostas a casos confirmados. 0 monitoramento consiste em acompanhar os casos por consultas via telefone, mensagens de texto ou até mesmo pessoalmente para reportar febre ou aparecimento de outros sintomas por um período de 14 dias (BURKE et al., 2020). As medidas de contenção adotadas, como isolamento e quarentena do paciente, controles de barreiras sanitárias nas fronteiras e medidas de precaução são consideradas eficazes para minimizar a propagação do vírus (NG et al., 2020). Diante disso, as startups APP2B, Hoobox e Radsquare desenvolveram tecnologias de mapeamento de pacientes infectados, baseadas em geoprocessamento (STARTUPSVSCOVID19, 2020; ALISSON, 2020a).

Outro modo de prevenção contra a COVID-19 é o uso de máscaras e equipamentos de proteção individual (EPIs), além da desinfecção regular de objetos e locais públicos (LUAN et al., 2020). Assim, muitas startups se empenharam em desenvolver soluções para a desinfecção de objetos e locais. Uma alternativa é a desinfecção de ambientes e equipamentos por luz ultravioleta, tais como o equipamento \#ComprasSemCorona, desenvolvido por dois empreendedores independentes, que já está sendo utilizado em supermercados de Brasília, e o sistema de desinfecção Hygis desenvolvido pela startup UVTRONIC (JORNAL DE BRASÍLIA, 2020; SIMI, 2020). Outra proposta adotada pela Panozon Ambiental emprega gás ozônio para desinfecção de EPI’s e máscaras (MOURA, 2020a). Ainda nesse contexto, a empresa New Hospital desenvolveu um sistema de controle de esterilização e rastreabilidade de materiais hospitalares (SIMI, 2020).

O uso de equipamentos de proteção individual é recomendado aos profissionais de saúde, principalmente ao prestar atendimento a indivíduos infectados e quando há a execução de procedimentos que geram aerossóis (DI GENNARO et al., 2020). No entanto, o acesso a esses equipamentos tem sido motivo de preocupação, devido à alta demanda global, resultando na escassez deste tipo de material em muitos países (HOPMAN; ALLEGRANZI; MEHTAR, 2020). Diante desta situação, algumas startups, como a ChemBioNano, a Trion 3D, a 3D Lopes, a MakerSpace e a Compass 3D, têm desenvolvido produtos de proteção que possam atender a classe médica e a população (MOURA, 2020b; SIMI, 2020).

\subsection{Inteligência Artificial (IA)}

Apesar dos grandes avanços na saúde pública, da previsão de doenças e do desenvolvimento de medicamentos, o surgimento de novas doenças infecciosas representa um grande desafio para a população. Os avanços na inteligência artificial (IA) permitem o processamento e a análise rápida de dados numerosos e complexos (PARK et al., 2020).

A IA pode ser empregada no contexto da pandemia com diferentes finalidades, como melhorar o controle de contenção do contágio viral, auxiliar na busca por tratamentos mais precisos, acompanhar os resultados de exames laboratoriais de indivíduos contaminados, e auxiliar o monitoramento médico acerca do quadro clínico do paciente (VAISHYA et al., 2020).

Utilizando a tecnologia de aprendizado profundo e a alta capacidade de extração de recursos, a IA auxilia 


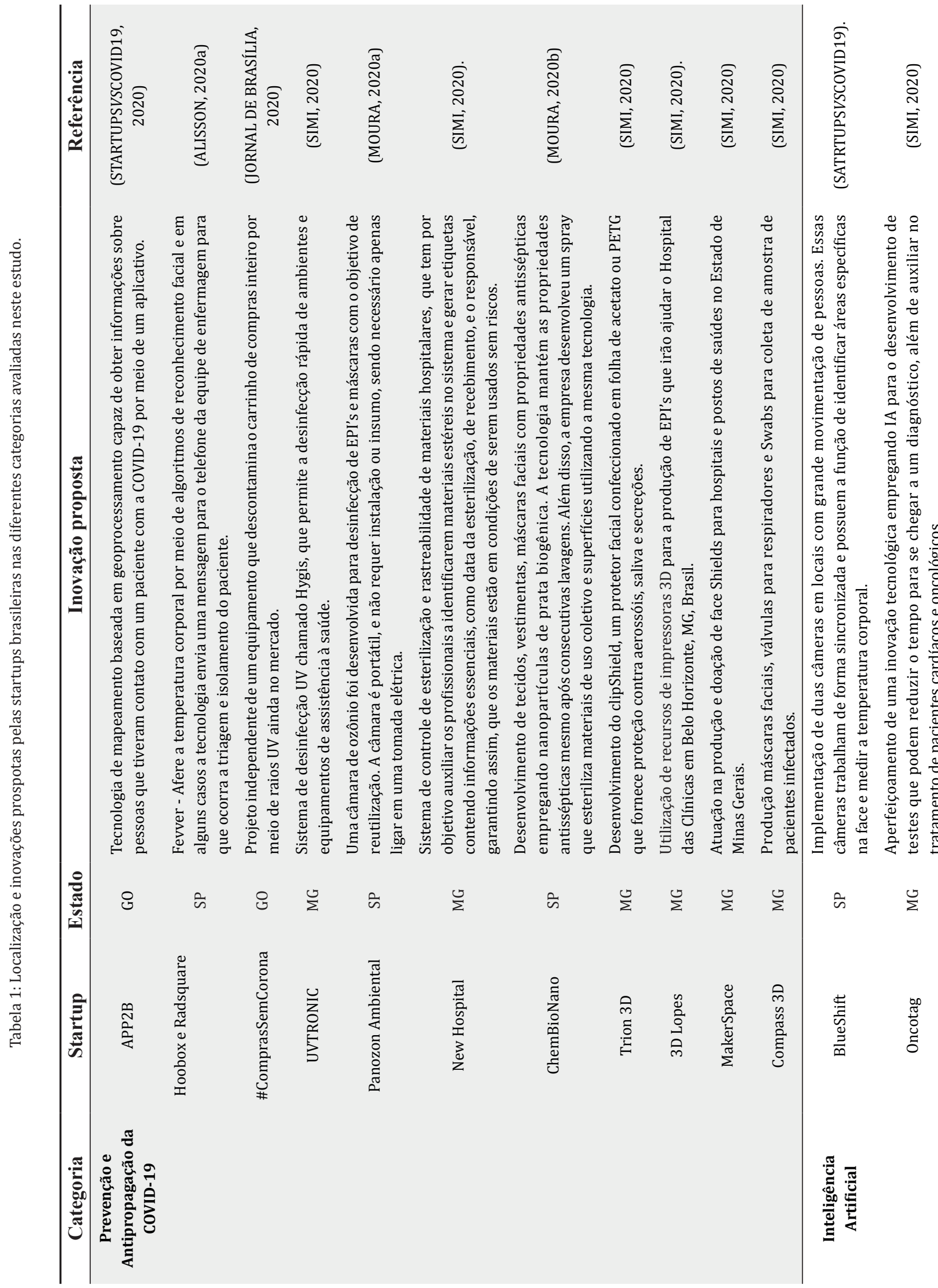




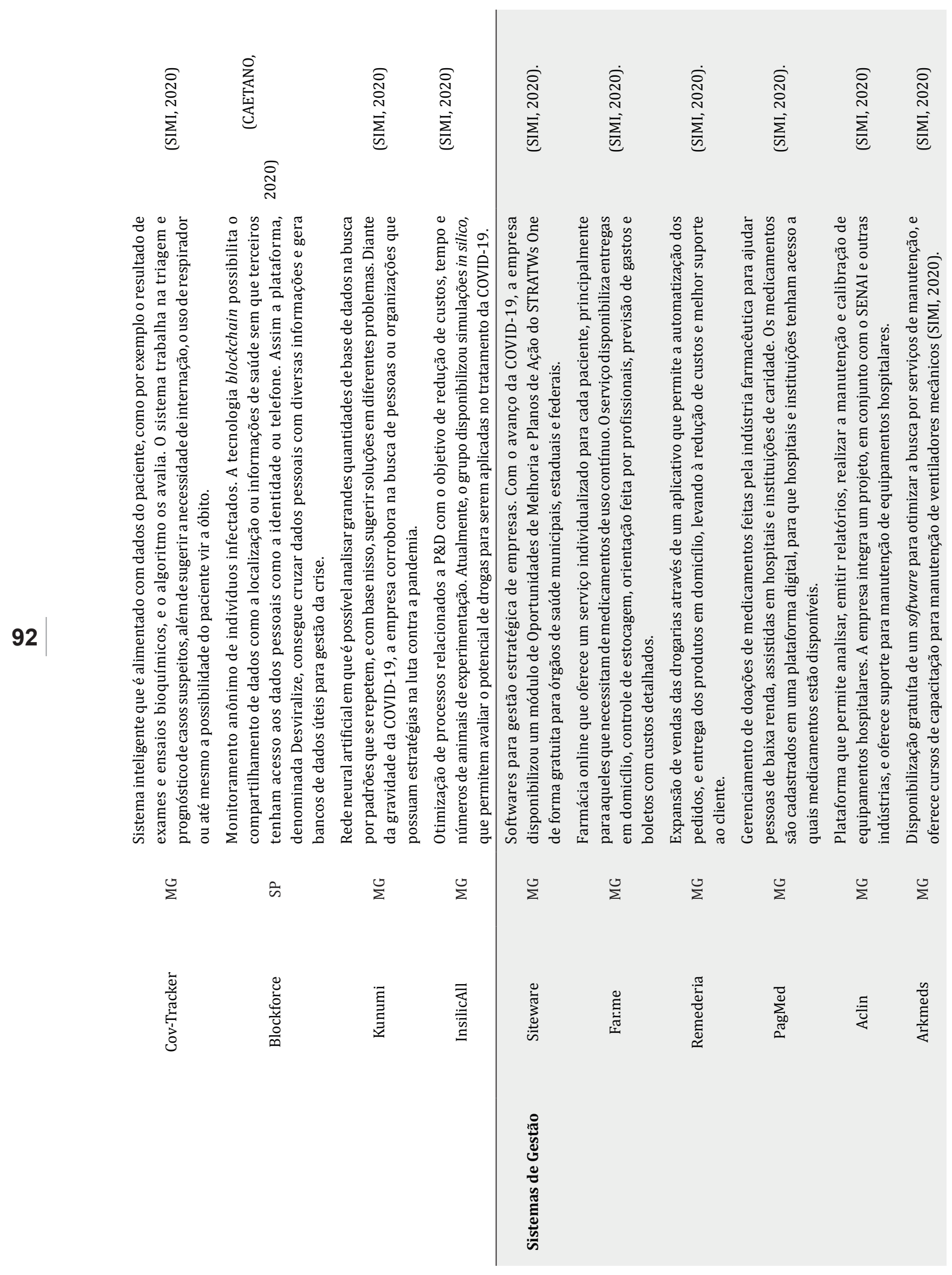




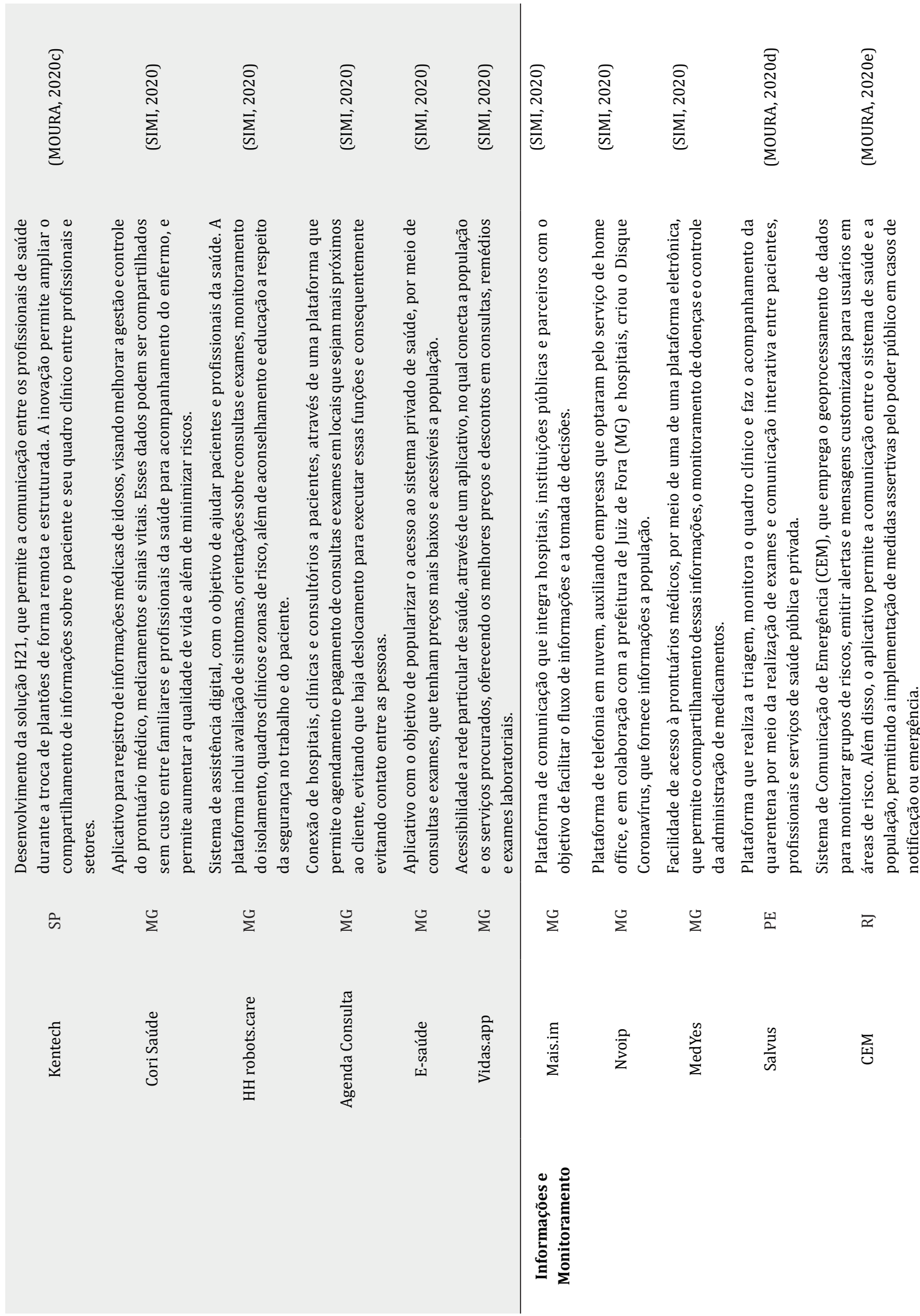




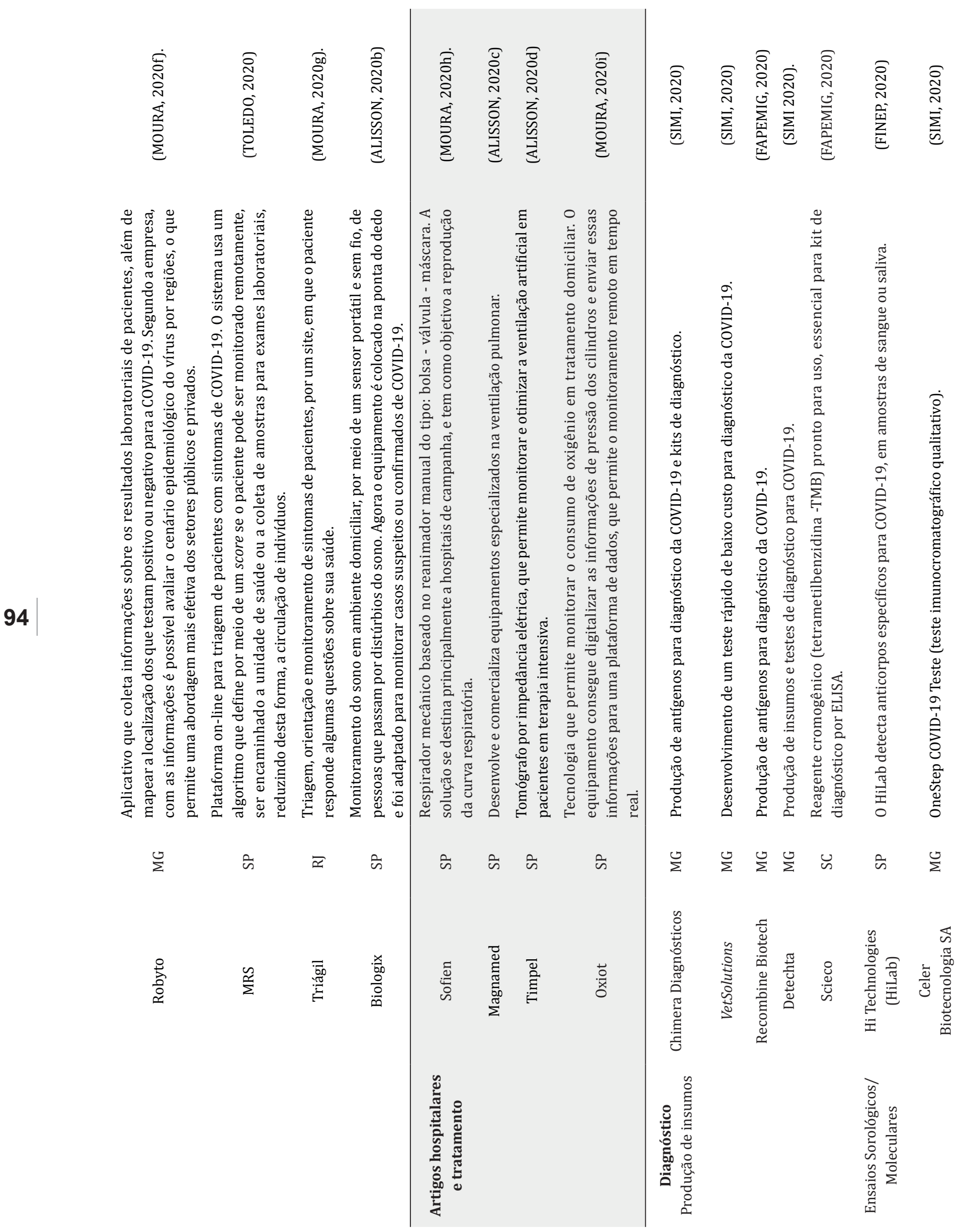




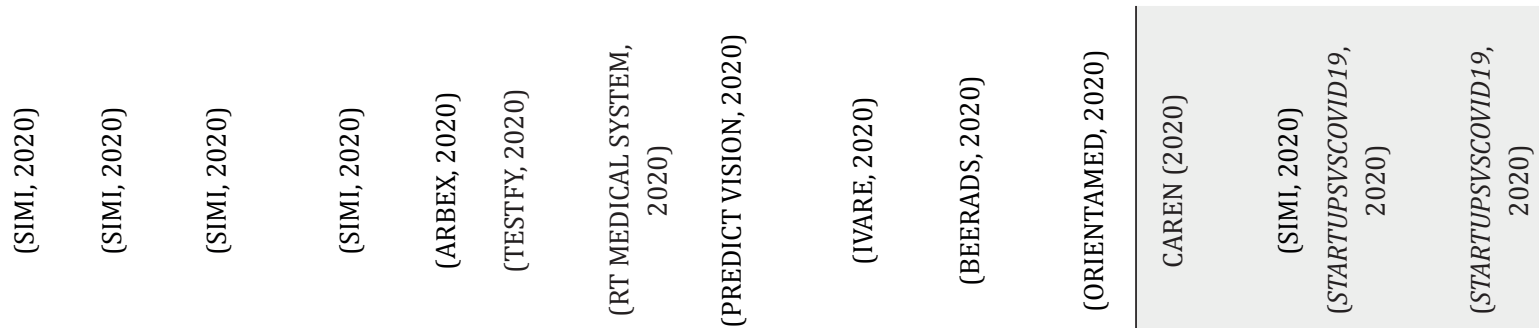

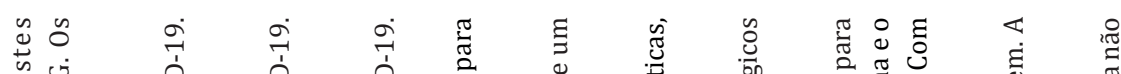

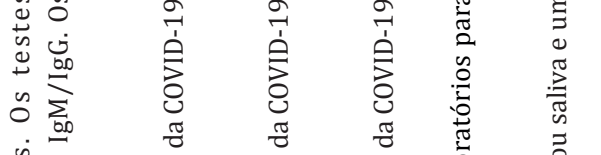

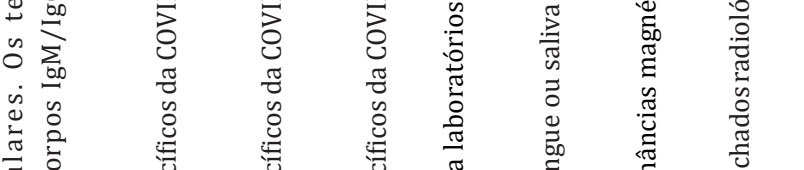

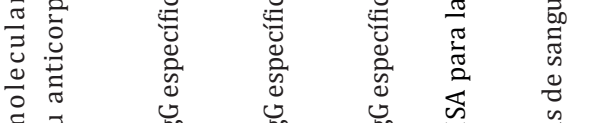

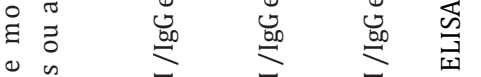

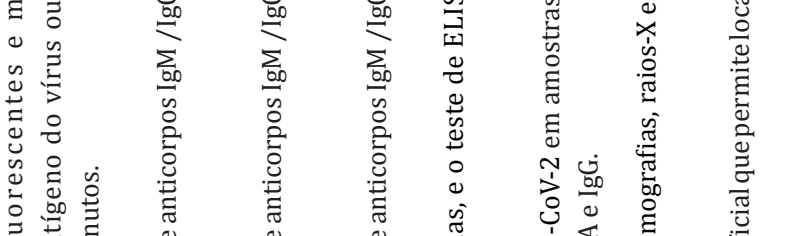

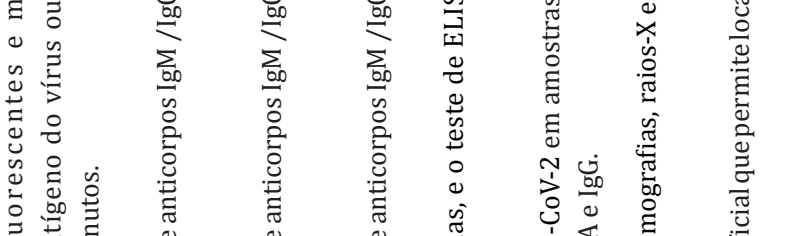

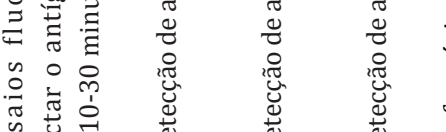

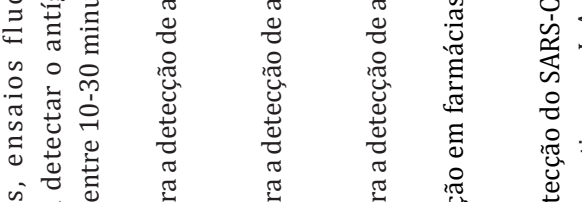

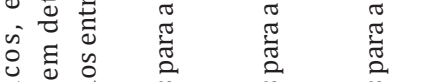

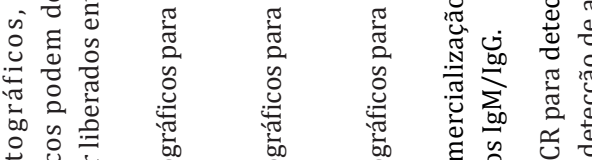

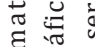

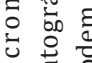

要

药

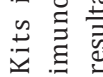
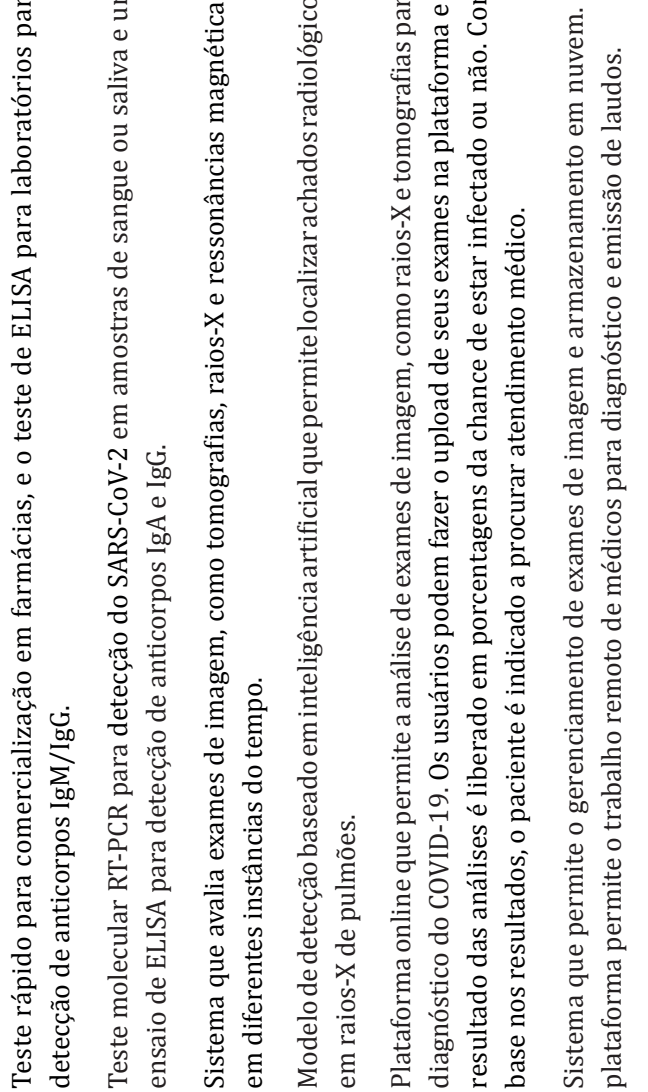

$\approx \pi$
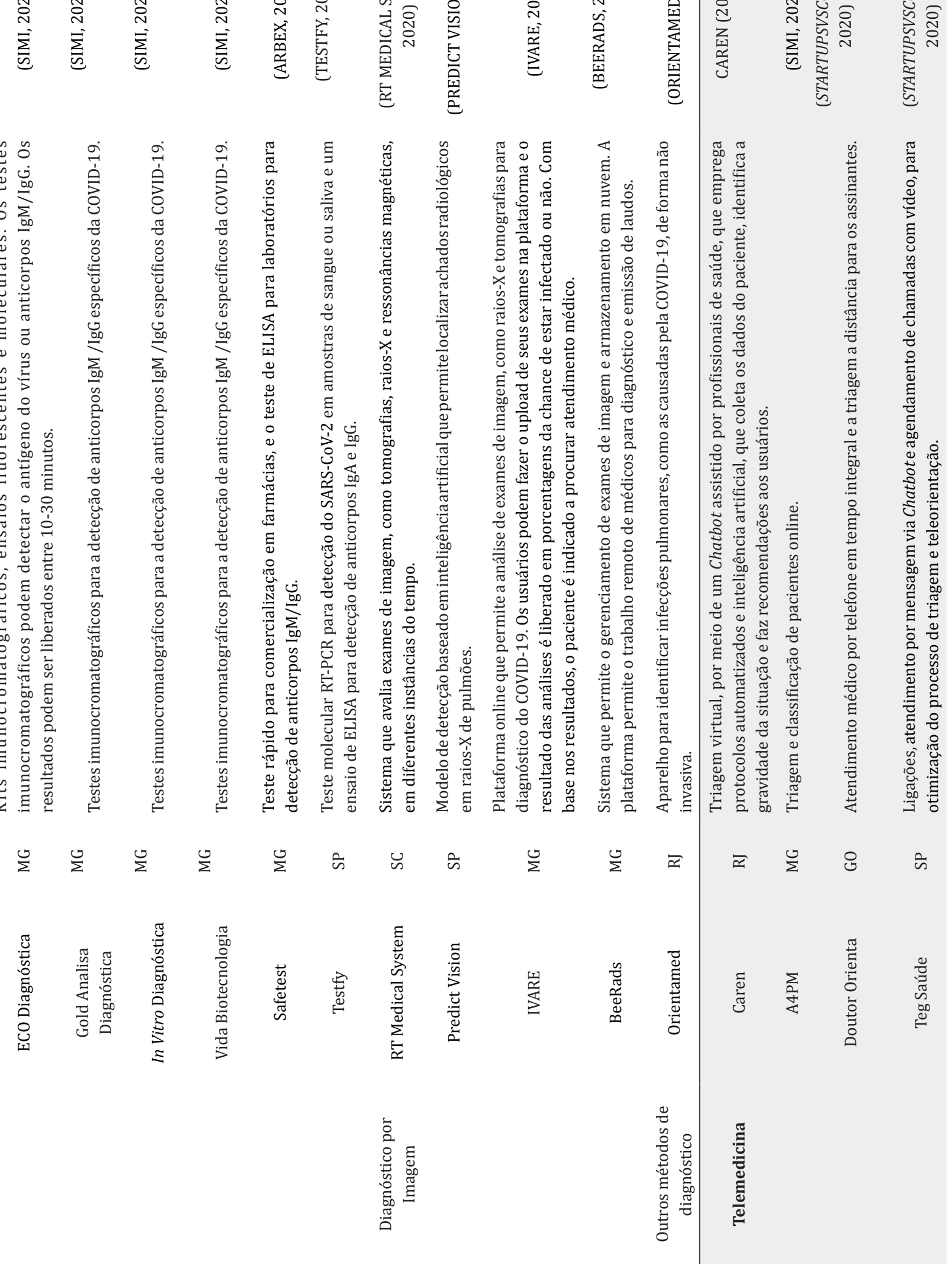


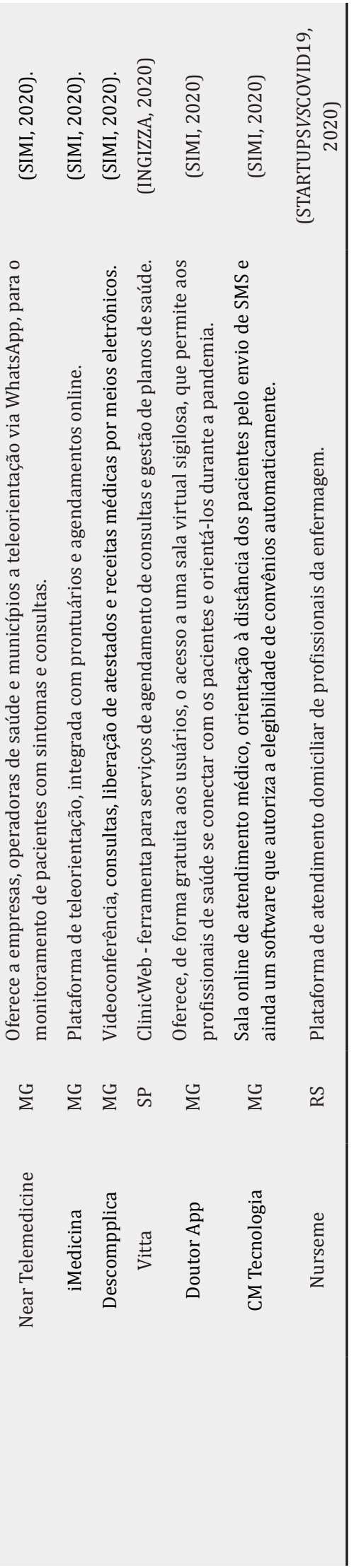

diversas startups no desenvolvimento de produtos com essa tecnologia. 0 resultado é a solução de alguns problemas e a minimização dos impactos advindos da crise na saúde pública, como por exemplo, a iniciativa da startup Kunumi (SIMI, 2020). Além disso, sistemas para avaliar sinais e sintomas de COVID-19 são extremamente importantes para triagem em grande escala em um curto período. As startups Oncotag, Cov-Tracker fornecem soluções nesse segmento (SIMI, 2020).

Outra aplicabilidade da IA consiste no monitoramento remoto de pessoas para identificação de casos suspeitos de COVID-19. Essa tecnologia é empregada nas startups BlueShift e Blockforce (SATRTUPSVSCOVID19; CAETANO, 2020).

A IA também foi reconhecida por ter influência no desenvolvimento de medicamentos, sendo considerada uma grande ferramenta para o mercado farmacêutico (ADLY; ADLY; ADLY, 2020). Assim, a InsilicAll otimiza processos para avaliar o potencial de novas drogas para o tratamento da COVID-19 (SIMI, 2020).

\subsection{Sistemas de Gestão}

Para melhorar o fluxo de atendimento de pacientes, é necessário otimizar a gestão dos serviços saúde. Ferramentas de gestão em saúde incluem o planejamento estratégico, visando melhorar a gerência de hospitais e clínicas nas redes de saúde privada e pública, principalmente do Sistema Único de Saúde (SUS). 0 planejamento estratégico, revela a necessidade da comunicação para que haja uma otimização da gestão, e que não ocorra o acúmulo ou escassez de recursos em setores específicos ou regiões, devido à desigualdade socioeconômica exorbitante vivenciada no Brasil (RODRIGUEZ-MORALES et al., 2020).

Dentro da gestão, é possível indicar diversas áreas que requerem atenção, novas estratégias de uso e logística. Dentre estas podemos citar: área de equipamentos hospitalares (aquisição ou manutenção de equipamentos), medicamentos (aquisição, estoque e distribuição), acesso a informações (dados hospitalares, laboratoriais e de prontuários), gestão de profissionais e monitoramento de pacientes (DEHNING et al., 2020).

Em meio a este cenário de crise, novas demandas surgiram para os sistemas de gestão em saúde. Com o objetivo de solucionar problemas e melhorar esses sistemas, 
algumas startups brasileiras desenvolveram novas estratégias e ideias inovadoras. A Siteware é uma empresa que fornece softwares para gestão estratégica de empresas. Com o avanço da COVID-19, a empresa disponibilizou um módulo de Oportunidades de Melhoria e Planos de Ação do STRATWs One de forma gratuita para órgãos de saúde municipais, estaduais e federais (SIMI, 2020).

$\mathrm{Na}$ área de gestão de medicamentos, as startups Far.me, PagMed e Remederia visam garantir que medicamentos, pincipalmente os de uso contínuo e assistência farmacêutica estejam disponíveis para a população (SIMI, 2020). Já o objetivo de E-saúde, Vidas.app e Agenda Consulta, é oferecer acessibilidade ao sistema privado de saúde, através de um aplicativo que conecta a população aos serviços procurados (SIMI, 2020). Em relação à gestão de equipamentos hospitalares, as startups Aclin e Arkmeds oferecem soluções nesse segmento (SIMI, 2020). Para ampliar o compartilhamento de dados sobre pacientes entre profissionais e setores, as startups Kentech, Cori Saúde e HH robots.care desenvolveram serviços de gestão ao acesso à informação (MOURA, 2020c; SIMI, 2020).

\subsection{Informações e Monitoramento}

O sistema de saúde necessita otimizar o seu funcionamento, para atender a demanda de acesso aos serviços de saúde em meio a pandemia. No entanto, para que isto ocorra, é imprescindível que a informação e monitoramento das redes hospitalares e das demais áreas da saúde sejam constantemente atualizadas (UDUGAMA et al., 2020). Estas informações devem ser adquiridas a partir de fontes confiáveis, que possuam elevados níveis de precisão em relação aos dados obtidos, para que desta forma, seja possível a identificação de limites, possibilidades e estratégias para tomadas de decisões (KAMEL BOULOS; GERAGHTY, 2020).

Nesse sentido, para auxiliar na prevenção da doença, são feitos mapeamentos das zonas de risco, avaliação de potenciais focos de infecção e formas de transmissão do vírus. Já em relação ao controle e tratamento, é feita a vigilância de redes hospitalares, avaliação dos serviços oferecidos e a contabilização dos números de pessoas infectadas, curadas e mortas. Esses números são necessários para novas estratégias de contingência e para alertar a população em relação ao avanço da COVID-19 (UDUGAMA et al., 2020).
Diante da necessidade de aprimoramento, da fiscalização da rede de saúde e o compartilhamento rápido e eficiente de dados, algumas startups brasileiras apresentam iniciativas para melhoria do sistema de monitoramento e informação. Perante à esse cenário a Mais.im facilita a comunicação entre hospitais e instituições públicas, a MedYes simplifica o acesso à prontuários, e a Nvoip propõe uma plataforma de telefonia em nuvem (SIMI, 2020). Outras startups oferecem soluções de acompanhamento e monitoramento de pacientes e casos suspeitos, baseados em geolocalização, como por exemplo a Salvus, CEM, Robyto, MRS - Modular Research System, Triágil e Biologix (MOURA, 2020d-g; TOLEDO, 2020; ALISSON, 2020b).

\section{Artigos hospitalares e tratamento}

A ventilação mecânica também conhecida por suporte ventilatório é a técnica de assistência à vida a curto prazo, e vem sendo indicada para pacientes com quadro de síndrome do desconforto respiratório aguda (SDRA) em casos de COVID-19. 0 método propõe a manutenção das trocas gasosas, o alívio da musculatura pulmonar, a minimização do desconforto ao respirar, dentre outras melhorias, que têm o intuito de reduzir o trabalho respiratório (PETTENUZZO; FAN, 2017; SILVA et al., 2020).

$\mathrm{Na}$ crescente luta contra a atual pandemia, os sistemas mundiais de saúde apresentam como limitação o acesso a ventiladores mecânicos, tanto nos programas públicos de saúde quanto nos privados (SILVA et al., 2020). Nesse contexto, as startups se destacam no desenvolvimento tecnológico na área da medicina, criando soluções com o intuito de suprir a elevada demanda de respiradores mecânicos tradicionais.

O respirador mecânico desenvolvido pela empresa Sofien, se diferencia dos ventiladores tradicionais invasivos, por ser um respirador baseado no reanimador manual do tipo: bolsa - válvula - máscara. Além disso, tem como inovação a capacidade de reproduzir a curva respiratória de forma personalizada, devido à inovação realizada na peça responsável pelo movimento alternado do equipamento, produzido em uma impressora 3D (MOURA, 2020h).

Uma possibilidade de ampliar o tratamento para os pacientes com a COVID-19, e para aqueles que possuem problemas respiratórios graves é a utilização de respiradores domésticos (SUMM et al., 2020). A oxigenotera- 
pia domiciliar pode oferecer diversos benefícios para os pacientes quando abordada de forma correta (SHEBL; MODI; CATES, 2020). Nesse sentido, a tecnologia disponibilizada pela Oxiot permite facilitar o atendimento de pacientes em casos graves de COVID-19 ou em tratamento com oxigênio, devido ao monitoramento em tempo real remoto, facilitando a logística de substituição de cilindros tanto para pacientes e familiares, quanto para fornecedores de gás medicinal e empresas de Home Care (MOURA, 2020i).

Após a instituição da ventilação mecânica em um paciente, este precisa ser monitorado a fim de se avaliar o momento ideal para retirada do suporte de ventilação, e liberar o equipamento para um próximo paciente (TOBIN, 2020). A utilização de um tomógrafo por impedância elétrica como o desenvolvido pela Timpel, permite avaliar a evolução do paciente no leito quanto à dependência da ventilação mecânica, o que permite otimizar o uso e direcionar os equipamentos para os casos mais graves (ALISSON, 2020d).

0 enfrentamento da COVID-19 tem sido marcado pela tomada de medidas que visem mitigar os riscos e reduzir a letalidade da doença. Uma destas medidas consiste em apoiar o desenvolvimento e fabricação de ventiladores mecânicos com tecnologias mais acessíveis e que não dependam de materiais importados (HOLANDA e PINHEIRO, 2020). Nesse sentido, se destaca a iniciativa da Magnamed, uma empresa nacional que atua no desenvolvimento e comercialização de equipamentos para ventilação pulmonar (ALISSON, 2020c).

Devido ao alto custo para montar e equipar um leito de UTI, a inovação e o desenvolvimento de produtos hospitalares são essenciais, especialmente neste momento de crise. Contudo, estes equipamentos devem ser avaliados quanto ao seu desempenho, qualidade dos materiais e validação, requisitos essenciais a produtos da área da saúde.

\section{DIAGNÓSTICO}

\section{Produção de insumos}

De acordo com a OMS, uma das áreas de prioridades em pesquisa é o diagnóstico para COVID-19 (CALLAHAN et al., 2020; MAGNO et al.,2020). Com os avanços da biologia molecular, a detecção de ácido nucleico tem sido um dos métodos mais empregados para detecção de SARS-
-CoV-2, em que se destaca a reação em cadeia da polimerase quantitativa baseada em transcriptase reversa (RT-qPCR) (LI et al., 2020). No entanto, há dificuldades na obtenção de insumos para os testes moleculares, uma vez que estes se tornaram uma necessidade global produzido em uma impressora 3D (MOURA, 2020h).

Uma alternativa aos ensaios moleculares, são os ensaios sorológicos para detecção de anticorpos empregando proteínas recombinantes que, podem auxiliar na vigilância epidemiológica. Este tipo de ensaio permite o rastreio de indivíduos doentes e recuperados (UDUGAMA et al., 2020). Nessa perspectiva, algumas startups estão desenvolvendo iniciativas para atender esta necessidade no Brasil, visto que, grande parte dos insumos, como os antígenos recombinantes, empregados nos ensaios sorológicos, são importados.

Um exemplo é a atuação da Chimera Diagnósticos, que trabalha no desenvolvimento de antígenos recombinantes nacionais, que no atual cenário da pandemia, se uniu a startup VetSolution, que atua no ramo de imunobiológicos e novas estratégias diagnósticas para saúde humana e animal, para desenvolverem de um teste rápido nacional de baixo custo para a COVID-19 cuja tecnologia será disponibilizada para o SUS (SIMI, 2020).

Outras startups que possuem iniciativas semelhantes, e estão atuando no desenvolvimento de novos antígenos e kits de diagnóstico para SARS-CoV-2, são a Recombine Biotech e a startup Detechta (FAPEMIG, 2020; SIMI 2020). Além destas empresas, pode-se destacar a Scienco Biotech, que produz reagentes para atender a demanda da indústria nacional de diagnósticos in vitro (FAPEMIG, 2020).

O desenvolvimento de insumos para kits de diagnóstico é um passo essencial para contribuição da ampliação da testagem e o diagnóstico correto da COVID-19. Esse é um desafio do Brasil e do mundo, para que medidas de saúde sejam implementadas de forma adequada.

\section{Ensaios sorológicos e moleculares}

Várias startups e empresas brasileiras tem direcionado esforços no desenvolvimento de testes rápidos para o diagnóstico da COVID-19. As principais vantagens deste tipo de teste são: o tempo de realização e obtenção dos resultados (10-30 minutos para teste rápido e 2-3 horas para ensaios de ELISA) e baixo custo quando comparado aos testes moleculares (NOGUEIRA et al., 2020). 
A Celer Biotecnologia S.A. disponibilizou o OneStep COVID-19, que é um teste imunocromatográfico qualitativo que permite identificar de forma rápida se o paciente está infectado pelo vírus (SIMI, 2020). Já a Gold Analisa Diagnóstica, In Vitro Diagnóstica e a Vida Biotecnologia são empresas que oferecem testes imunocromatográficos para a detecção de anticorpos IgM /IgG específicos da COVID-19 (SIMI, 2020). Esse tipo de teste permite diferenciar a fase aguda e tardia da doença.

Outra empresa que se destaca em fornecer um teste rápido, para farmácias e empresas, é a startup Hi Technologies (HiLab). O teste detecta anticorpos IgM e IgG, em amostras de sangue, e tem como diferencial o envio dos dados coletados à uma central que emite o resultado em 10 minutos (FINEP, 2020).

A Safetest também desenvolveu um teste sorológico totalmente nacional que detecta anticorpos $\operatorname{IgM}$ e IgG específicos. A empresa irá disponibilizar o teste rápido para comercialização em farmácias, e um teste de ELISA para laboratórios (ARBEX, 2020). Já a startup Testfy (2020), comercializa um teste de ELISA diferente do proposto pela Safetest, pois, o ensaio detecta anticorpos IgA específicos para SARS-CoV-2. Além disso, a empresa também oferece um método molecular de RT-PCR

A ECO Diagnóstica, oferece kits imunocromatográficos, ensaios fluorescentes e moleculares para diagnóstico da COVID-19. A empresa se destacou ao oferecer um teste rápido para detecção do antígeno de SARS-CoV-2 em amostras de nasofaringe, que pode ser realizado à partir do segundo dia de contaminação, com resultado entre 15-30 minutos (SIMI, 2020).

\section{Diagnóstico por Imagem}

Apesar do RT-PCR ser o padrão ouro de diagnóstico da COVID-19, exames complementares como a tomográfica computadorizada e raios-X, têm sido empregados para complementar o diagnóstico. Há relatos de casos de pacientes com resultados negativos no teste de RT-PCR e achados nos exames de imagens sugestivos de pneumonia viral, que posteriormente positivaram para a doença (AI et al., 2020).

De acordo com Shi e colaboradores (2020), exames de tomografia computadorizada seriadas em indivíduos infectados por SARS-CoV-2 permitem monitorar as alterações pulmonares e acompanhar o progresso da doença. 0 sistema desenvolvido pela startup RT Medical System (2020) permite fazer este tipo de acompanhamento.

É extremamente importante observar as características de achados pulmonares comuns da COVID-19 em exames de imagens. No entanto, a interpretação destes achados depende de conhecimento técnico. Nesse sentido, a tecnologia da Predict Vision (2020) e da IVARE (2020) se destacam, a primeira por permitir a detecção de achados radiológicos em exames de raios-X, por meio de inteligência artificial, auxiliando os profissionais no diagnóstico e a segunda, por analisar o resultados de exames de imagens e direcionar os pacientes a buscarem atendimento médico.

Visando a redução do risco de infecções e o isolamento social, as instituições de saúde estão compartilhando informações de forma remota. Uma vantagem da iniciativa da BeeRads (2020), é que a plataforma além de permitir o trabalho remoto, oferece a emissão de laudos.

\section{Outros métodos de diagnóstico}

Algumas tecnologias inovadoras estão sendo adaptadas para permitir a detecção de SARS-CoV-2. Um exemplo é a iniciativa da Orientamed (2020), que desenvolve equipamentos para monitorar doenças por meio de uma base de dados e algoritmos de inteligência artificial, como por exemplo, mensurar a glicemia em pacientes diabéticos através do sopro. A empresa está trabalhando em um aparelho para identificar infecções pulmonares, como as causadas pelo novo coronavírus, de forma não invasiva. A empresa pretende avaliar o protótipo para a COVID-19, e já conta com algumas parceiras. No entanto, ainda necessita de investimentos para os testes clínicos.

\section{Telemedicina}

Com a expansão da COVID-19, a telemedicina ganhou destaque, pois esta tecnologia permite prestar assistência e acompanhar o paciente de forma remota, principalmente pessoas dos grupos de risco, a fim de se reduzir os índices de contaminação (CALTON; ABEDINI; FRATKIN, 2020; SMITH et al., 2020). No Brasil, o Conselho Federal de Medicina (CFM, 2020) autorizou o uso da telemedicina enquanto durar o combate à pandemia. A telemedicina poderá ser exercida com as seguintes finalidades: teleorientação, telemonitoramento e teleconsulta. 
Diversas startups como a Caren, A4PM, Doutor Orienta, Teg Saúde, Near Telemedicine e iMedicina, atuam oferecendo a triagem e teleorientação remota à pacientes de COVID-19 por meio de plataformas. Algumas empresas, como a Caren (2020), realiza a coleta dos dados e classificam os pacientes utilizando protocolos automatizados e inteligência artificial, com base nas recomendações estabelecidas pelo Ministério da Saúde do Brasil.

0 atendimento via telefone, por meio de aplicativos de mensagens, como Whats App, e o envio de SMS, são oferecidos por algumas startups como a Doutor Orienta, Teg Saúde e Near Telemedicine. Este tipo de atendimento tem sido empregado com o intuito de aumentar a acessibilidade e evitar a saturação de postos médicos e hospitais (STARTUPSVSCOVID19, 2020, SIMI, 2020). Outra vantagem das plataformas de telemedicina, como o serviço oferecido pela iMedicina e Vitta, é o acesso remoto aos prontuários dos pacientes e o agendamento de consultas online (INGIZZA, 2020; SIMI, 2020).

No entanto, as consultas por vídeos podem fornecer informações adicionais sobre os pacientes, como sintomas e avaliação de características da pele como rubor, palidez ou cianose. Ainda, pode ser considerada o meio mais indicado para pacientes com comorbidades, pessoas ansiosas e aquelas que são afetadas por condições sociais (GREENHALGH; KOH; CAR, 2020).

Nesse sentido, se destacam as inciativas das startups Teg Sáude, Vitta, Descompplica, Doutor App e CM Tecnologia, que durante a pandemia, oferecem consultas por vídeo aos usuários. Dentre estas iniciativas, se sobressaem as startups Descompplica e CM Tecnologia. A Descompplica por ser uma startup voltada para consumidores da classe C (SIMI, 2020). Já a CM Tecnologia, inovou ao oferecer além das consultas, um software que autoriza a elegibilidade de convênios automaticamente, evitando que o serviço seja feito manualmente quanto a aglomeração de pessoas nas salas de espera (SIMI, 2020).

Contudo, a consulta por meio de vídeo pode não ser adequada em algumas situações em que o paciente esteja em estado grave, e tenha a necessidade de exames físicos ou quando o paciente não possua capacidade de usar a tecnologia de forma adequada por alguma razão (GREENHALGH; KOH; CAR, 2020).

Alguns pacientes requerem cuidados especiais e atendimento domiciliar. Nesse sentido, destaca-se a Nurseme que possui uma plataforma que permite co- nectar profissionais da enfermagem à clientes que necessitam de atendimento domiciliar, atendendo principalmente estado do Rio Grande do Sul (STARTUPSVSCOVID19,2020). No entanto, a visita domiciliar deve seguir as diretrizes publicadas pela OMS, e avaliar se o ambiente da residência está adequado e se as medidas de prevenção estão sendo adotadas para receber os profissionais de saúde (ZHENG et al., 2020; WHO, 2020d)

\section{CONCLUSÃo}

Com o agravo da disseminação do novo coronavírus e a rápida evolução da pandemia, as ações coordenadas de saúde associadas ao desenvolvimento de novas tecnologias são essenciais para o enfrentamento desta crise. Os impactos causados pelo COVID-19 no setor da saúde e na economia ainda são incalculáveis.

Diante disso, a principal contribuição deste trabalho, foi destacar as ações e iniciativas inovadoras de algumas startups e empresas brasileiras para solucionar problemas, tais como: a falta de equipamentos de proteção individual e hospitalares, a triagem e o monitoramento da população, a melhoria do acesso à informações sobre cuidado, prevenção e aos serviços de saúde em meio a pandemia.

O desenvolvimento de tecnologia nacional no setor da saúde é fundamental para atender às necessidades da população, principalmente em cenários como este, em que há limitações no mercado em função do distanciamento social, do comprometimento da disponibilidade de suprimentos, além de problemas de logística e flutuações cambiais.

Apesar deste momento de incertezas, as startups e empresas possuem uma excelente oportunidade para empreender, principalmente ao empregar recursos como impressão 3D, inteligência artificial, geoprocessamento, internet e outras tecnologias, visando a redução de custos, a velocidade de produção e a qualidade dos serviços oferecidos.

As diferentes ações e iniciativas fornecidas pelas startups brasileiras reportadas neste estudo podem impactar diretamente na sociedade e no cotidiano de instituições públicas e privadas. No entanto, é necessário que haja incentivo governamental ou de forma privada para que algumas destas iniciativas possam alcançar, além do mercado interno, o mercado mundial. 
Financiamento do artigo: 0 presente trabalho foi realizado com apoio da Coordenação de Aperfeiçoamento de Pessoal de Nível Superior - Brasil (CAPES) Código de Financiamento 001. Este trabalho também foi financiado pelo Conselho Nacional de Desenvolvimento Científico e Tecnológico do CNPq, processos 300721/2019-6, 140388/2019-2, 314531/2018-1,
140367/2019-5, e concessão da Universidade Federal de São João del-Rei - UFSJ “PIE-COVID19”.

Agradecimentos: Os autores agradecem à Universidade Federal de São João Del Rei (UFSJ) e à Fundação de Amparo à Pesquisa do Estado de Minas Gerais (FAPEMIG) pelo apoio. Cristiane Bittencourt Barroso Toledo e Rosângela da Silva Lomeo pelo suporte e revisão do manuscrito. 


\section{REFERÊNCIAS}

ADLY, A. S.; ADLY, A. S.; ADLY, M. S. Approaches Based on Artificial Intelligence and the Internet of Intelligent Things to Prevent the Spread of COVID-19: Scoping Review. Journal of Medical Internet Research, v. 22, n. 8, p. e19104, 2020.

AHMED, F. et al. Why inequality could spread COVID-19. The Lancet Public Health, v. 5, n. 5, p. e240, 1 maio 2020.

AI, T. et al. Correlation of Chest CT and RT-PCR Testing in Coronavirus Disease 2019 (COVID-19) in China: A Report of 1014 Cases. Radiology, p. 200642, 26 fev. 2020.

ALISSON, E. Startups desenvolvem sistema que detecta febre a distância. Agência FAPESP, 2020a. Disponível em: <http:// https://agencia.fapesp.br/startups-desenvolvem-sistema-que-detecta-febre-a-distancia/32933/>. Acesso em: maio 2020.

ALISSON, E. Tecnologia permite monitorar a distância pacientes com suspeita ou sintomas brandos de COVID19. Agência FAPESP, 2020b. Disponível em: <http://agencia.fapesp.br/ tecnologia-permite-monitorar-a-distancia-pacientes-com-suspeita-ou-sintomas-brandos-de-covid-19/33015/ >. Acesso em: jun. 2020 .

ALISSON, E. Empresa apoiada pela FAPESP fornecerá ventiladores pulmonares para o Ministério da Saúde. Agência FAPESP, 2020c. Disponível em: <http://agencia.fapesp.br/ empresa-apoiada-pela-fapesp-fornecera-ventiladores-pulmonares-para-o-ministerio-da-saude/32934/ >. Acesso em: abr. 2020.

ALISSON, E. Tecnologia otimiza o uso de ventiladores pulmonares e leitos de UTI. Agência FAPESP, 2020d. Disponível em: $<$ http://agencia.fapesp.br/empresa-apoiada-pela-fapesp-fornecera-ventiladores-pulmonares-para-o-ministerio-da-saude/32934/ >. Acesso em: e abr. 2020.

ARBEX. G. EXCLUSIVO: Startup mineira desenvolve teste de Covid-19 que fica pronto em 15 minutos e custa menos de R $\$ 50$. FORBES, 2020. Disponível em: https://forbes.com.br/forbes-insider/2020/06/exclusivo-startup-mineira-desenvolve-teste-de-covid-19-que-fica-pronto-em-15-minutos-e-custa-menos-de-r-50/ Acesso: jun. 2020.

BEERADS. Plataforma de laudos médicos à distância. 2020. Disponível em: <https://beerads.app/>. Acesso em: abr. 2020.

BURKE, R. M. et al. Active Monitoring of Persons Exposed to Patients with Confirmed COVID-19 - United States, JanuaryFebruary 2020. MMWR. Morbidity and Mortality Weekly Report, v. 69, n. 9, p. 245-246, 6 mar. 2020.

CAETANO, R. Startup usa blockchain para monitorar infectados pelo coronavírus. Revista EXAME, 2020. Disponível em: <https://exame.com/tecnologia/startup-usa-blockchain-para-monitorar-infectados-pelo-coronavirus/>. Acesso: abr. de 2020
CALLAHAN, C. J. et al. Open Development and Clinical Validation of Multiple 3D-Printed Nasopharyngeal Collection Swabs: Rapid Resolution of a Critical COVID-19 Testing Bottleneck. Journal of Clinical Microbiology, 11 maio 2020.

CALTON, B. et al. Telemedicine in the Time of Coronavirus. Journal of Pain and Symptom Management, v. 60, n. 1, p. e12-e14, 1 jul. 2020

CAREN. Auto-avaliação de Coronavírus (COVID-19). Disponível em: < https://coronavirus.caren.app/pt-BR/attendance>. Acesso em: abr. 2020

CFM - CONSELHO FEDERAL DE MEDICINA DO BRASIL. Telemedicina: CFM reconhece possibilidade de atendimento médico a distância durante o combate à COVID-19. CFM, 2020. Disponível em: <https://portal.cfm.org.br/index.php?option=c o m_content\&vi e w = article \& id = 28636:2020-03-19-23-35-42\&catid=3>. Acesso em: maio 2020.

DEHNING, J. et al. Inferring change points in the spread of COVID-19 reveals the effectiveness of interventions. Science, v. 369, n. 6500 , p. eabb9789, 10 jul. 2020

DI GENNARO, F. et al. Coronavirus Diseases (COVID-19) Current Status and Future Perspectives: A Narrative Review. International Journal of Environmental Research and Public Health, v. 17, n. 8, p. 2690, 14 abr. 2020.

FAPEMIG - Fundação de Amparo à Pesquisa do Estado de Minas Gerais. FAPEMIG mapeia empresas dispostas a parcerias para soluções no combate ao coronavírus. Belo Horizonte, 2020. Disponível em:< https://fapemig.br/pt/noticias/341\#gsc. tab $=0>$ Acesso: abr. 2020

FINEP- Financiadora de Estudos e Pesquisas. Startup apoiada pela Finep desenvolve teste rápido para Covid-19. FINEP, 2020. Disponível em: <http://www.finep.gov.br/noticias/todas-noticias/6129-startup-apoiada-pela-finep-desenvolve-teste-rapido-para-covid-19>. Acesso em: maio 2020.

GORBALENYA, A. E. et al. The species Severe acute respiratory syndrome-related coronavirus: classifying 2019-nCoV and naming it SARS-CoV-2. Nature Microbiology, v. 5, n. 4, p. 536544, 2 abr. 2020 .

GREENHALGH, T.; KOH, G. C. H.; CAR, J. Covid-19: a remote assessment in primary care. BMJ, v. 368, p. m1182, 25 mar. 2020

GÜNER, R.; HASANOĞLU, İ.; AKTAȘ, F. COVID-19: Prevention and control measures in community. Turkish Journal of Medical Sciences, v. 50, n. SI-1, p. 571-577, 21 abr. 2020.

HALEEM, A.; JAVAID, M.; VAISHYA, R. Effects of COVID-19 pandemic in daily life. Current Medicine Research and Practice v. 10 , n. 2 , p. $78-79$, mar. 2020

HOLANDA, M. A; PINHEIRO, B. V. Pandemia por COVID-19 e ventilação mecânica: enfrentando o presente, desenhando o 
futuro. Jornal Brasileiro de Pneumologia, v. 46, n. 4, p. e20200282-e20200282, 2020

HOPMAN, J.; ALLEGRANZI, B.; MEHTAR, S. Managing COVID-19 in Low- and Middle-Income Countries. JAMA, v. 323, n. 16, p. 1549, 28 abr. 2020.

INGIZZA, C. Startup Vitta lança software de telemedicina gratuito para médicos. EXAME, 2020. Disponível: < https://exame.com/pme/startup-vitta-lanca-software-de-telemedicina-gratuito-para-medicos/> Acesso em: abr. 2020.

IVARE - Soluções em Inteligência Artificial aplicada a Imagens, Dados e Padrões. IVARE, 2020. Disponível em: <https: https:// covid19.ivare.com.br/> Acesso em: abr.2020.

JORNAL DE BRASÍLIA. Startup de Brasília cria "Descontaminador de Compras” contra o COVID-19. Brasília, 2020. Disponíve em: < https://jornaldebrasilia.com.br/cidades/startup-de-brasilia-cria-descontaminador-de-compras-contra-o-covid-19/> Acesso em: maio 2020.

KAMEL BOULOS, M. N.; GERAGHTY, E. M. Geographical tracking and mapping of coronavirus disease COVID-19/severe acute respiratory syndrome coronavirus 2 (SARS-CoV-2) epidemic and associated events around the world: how 21st century GIS technologies are supporting the global fight against outbr. International Journal of Health Geographics, v. 19, n. 1, p. 8 11 dez. 2020

$\mathrm{LI}$, X. et al. Molecular immune pathogenesis and diagnosis of COVID-19. Journal of Pharmaceutical Analysis, v. 10, n. 2, p. 102-108, 1 abr. 2020a.

LUAN, R. S. et al. Epidemiology, Treatment, and Epidemic Prevention and Control of the Coronavirus Disease 2019: a Review. Journal of Sichuan University. v.51, n.2, p.131-138, 1 mar. 2020.

MAGNO, L. et al. Desafios e propostas para ampliação da testagem e diagnóstico para COVID-19 no Brasil. Ciência \& Saúde Coletiva, v. 25, p. 3355-3364, 2020.

MOURA, M. Câmara de ozônio para desinfecção de EPIs e máscaras para reutilização da startup Panozon Ambiental. Inova Unicamp, Campinas, 2020a. Disponível em: <https://www. inova.unicamp.br/solucoes-covid-19/camara-de-ozonio-para-desinfeccao-de-epis-e-mascaras-para-reutilizacao-da-startup-panozon-ambiental/>. Acesso em: maio 2020.

MOURA, M. Tecnologia antisséptica para tecidos da startup ChemBioNano. Inova Unicamp, Campinas, 2020b. Disponível em:<https://www.inova.unicamp.br/solucoes-covid-19/ camara-de-ozonio-para-desinfeccao-de-epis-e-mascaras-para-reutilizacao-da-startup-panozon-ambiental/>. Acesso em: maio 2020.
MOURA, M. Solução H21 para passagem de plantão. Inova Unicamp, Campinas, 2020c. Disponível em: <https://www.inova. unicamp.br/solucoes-covid-19/solucao-h21-para-passagem-de-plantao/>. Acesso em: maio 2020.

MOURA, M. Aplicativo de monitoramento de pacientes da Covid-19 em tempo real de Salvus. Inova Unicamp, Campinas, 2020d. Disponível em: <https://www.inova.unicamp.br/solucoes-covid-19/aplicativo-de-monitoramento-de-pacientes-de-covid-19-em-tempo-real-da-salvus/> Acesso em: maio 2020.

MOURA, M. Aplicativo Saúde CEM para Comunicação de Emergência. Inova Unicamp, Campinas, 2020e. Disponível em: <https://www.inova.unicamp.br/solucoes-covid-19/aplicativo-de-monitoramento-de-pacientes-de-covid-19-em-tempo-real-da-salvus/> Acesso em: maio 2020.

MOURA, M. Aplicativo CoroSai para mapeamento do Coronavírus por região. Inova Unicamp, Campinas, 2020f. Disponível em: <https://www.inova.unicamp.br/solucoes-covid-19/ aplicativo-corosai-para-mapeamento-do-coronavirus-por-regiao/ > Acesso em: maio 2020.

MOURA, M. Solução de Triagem, Orientação e Monitoramento digital da startup Triágil. Inova Unicamp, Campinas, $2020 \mathrm{~g}$. Disponível em:< https://www.inova.unicamp.br/solucoes-covid-19/solucao-de-triagem-orientacao-e-monitoramento-digital-da-startup-triagil/> Acesso em: maio 2020.

MOURA, M. Respirador mecânico baseado em Ambu da SOFIEN. Inova Unicamp, Campinas, 2020h. Disponível em: <https://www.inova.unicamp.br/solucoes-covid-19/respirador-mecanico-baseado-em-ambu-da-sofien/> Acesso em: maio 2020.

MOURA, M. Solução Oxiot para monitoramento de consumo de oxigênio medicinal. Inova Unicamp, Campinas, 2020i. Disponível em: <https://www.inova.unicamp.br/solucoes-covid-19/solucao-oxiot-para-monitoramento-de-consumo-de-oxigenio-medicinal/>. Acesso em: maio 2020.

NG, Y. et al. Evaluation of the Effectiveness of Surveillance and Containment Measures for the First 100 Patients with COVID-19 in Singapore - January 2-February 29, 2020. MMWR. Morbidity and Mortality Weekly Report, v. 69, n. 11, p. 307 311, 20 mar. 2020.

NICOLA, M. et al. The socio-economic implications of the coronavirus pandemic (COVID-19): A review. International Journal of Surgery, v. 78, p. 185-193, 1 jun. 2020.

NOGUEIRA, L. et al. O envolvimento da Ciência Brasileira no diagnóstico da COVID-19. Ciência em Movimento, v. 22, n. 43, p. 161,2020

ORIENTAMED. Salvando vidas pelo sopro. 2020. Disponível em: < https://www.triagemdigital.com/>. Acesso em: abr 2020 . 
PARK, Y. et al. Emergence of New Disease: How Can Artificial Intelligence Help? Trends in Molecular Medicine, v. 26, n. 7, p. 627-629, jul. 2020 .

PETTENUZZO, T.; FAN, E. 2016 Year in Review: Mechanical Ventilation. Respiratory Care, v. 62, n. 5, p. 629-635, 24 maio 2017.

PREDICT VISION. Plataforma cognitiva para suporte a decisão médica. 2020. Disponível em: <http://www.predict.vision>. Acesso em: abr.2020.

RODRIGUEZ-MORALES, A. J. et al. COVID-19 in Latin America: The implications of the first confirmed case in Brazil. Travel Medicine and Infectious Disease, v. 35, p. 101613, maio 2020.

RT MEDICAL SYSTEMS. RT Connect. 2020. Disponível em: < https://rtmedical.com.br/covid19>. Acesso em: abr. 2020.

SATARTUPSVSCOVID19 - Plataforma de cadastro de tecnologias para enfrentamento da COVID-19. SATARTUPSVSCOVID19, 2020. Disponível em: < https://startupsvscovid19. com/>. Acesso: abr. de 2020 .

SHEBL, E.; MODI, P.; CATES, T. D. Home Oxygen Therapy. StatPearls Publishing, 2020. Disponível em:<https://www.ncbi. nlm.nih.gov/books/NBK532994/>. Acesso em: maio 2020.

SHI, H. et al. Radiological findings from 81 patients with COVID-19 pneumonia in Wuhan, China: a descriptive study. The Lancet Infectious Diseases, v. 20, n. 4, p. 425-434, 1 abr. 2020.

SILVA, M. B. DA. et al. Enfrentamento à Covid-19: um mapeamento das patentes de ventiladores mecânicos. Cadernos de Prospecção, v. 13, n. 2 COVID-19, p. 526, 16 abr. 2020.

SIMI - Sistema Mineiro de Inovação. Inovação contra a COVID-19. Inovações Mineiras contra os efeitos diretos e indiretos da COVID-19. SIMI Reports, 2020. Disponível em:<https://docs.google.com/ presentation/d/e/2PACX-1vTkdr90rC7Fr2DNPxhcjQ6TK-zgXNLp5kua8liKkwXmx1txmBbJSPq616MA-XwXj977-2euASip_3ct/pub? start=false \&loop $=$ false $\&$ delayms $=3000 \&$ slide $=i d$. g52e335adac_1_53>. Acesso: maio 2020.

SMITH, A. C. et al. Telehealth for global emergencies: Implications for coronavirus disease 2019 (COVID-19). Journal of Telemedicine and Telecare, v. 26, n. 5, p. 309-313, 1 jun. 2020.

SOHRABI, C. et al. World Health Organization declares global emergency: A review of the 2019 novel coronavirus (COVID-19). International Journal of Surgery, v. 76, p. 71-76, 1 abr. 2020.
SUMM, O. et al. COVID-19-Pandemie: strukturierte Erweiterung von Beatmungskapazitäten mithilfe von Heimrespiratoren. Der Anaesthesist, v. 69, n. 5, p. 323-330, 29 maio 2020

TESTFY. Fazendo ciência hoje, para promover a tecnologia de amanhã. TESTFY, 2020. Disponível em: https://www.testfy. com.br/. Acesso: maio 2020 .

TOBIN, M. J. Basing Respiratory Management of COVID-19 on Physiological Principles. American Journal of Respiratory and Critical Care Medicine, v. 201, n. 11, p. 1319-1320, 2020.

TOLEDO, K. Serviço de agilização de serviços on-line para COVID-19 em São Caetano do Sul. Agência FAPESP. São Paulo, 2020. Disponível em: <http://agencia.fapesp.br/servico-on-line-agiliza-testagem-para-covid-19-em-sao-caetano-do-sul/32970/> . Acesso: abr. 2020.

UDUGAMA, B. et al. Diagnosing COVID-19: The Disease and Tools for Detection. ACS Nano, v. 14, n. 4, p. 3822-3835, 28 abr 2020 .

VAISHYA, R. et al. Artificial Intelligence (AI) applications for COVID-19 pandemic. Diabetes and Metabolic Syndrome Clinical Research and Reviews, v. 14, n. 4, p. 337-339, 1 jul 2020.

WHO - World Health Organization. Coronavirus disease (COVID-19) pandemic, 2020a. Disponível em: <https://www who.int/emergencies/diseases/novel-coronavirus-2019> Acesso: mar. 2020.

WHO - World Health Organization. Coronavirus disease 2019 (COVID-19). 2020b. Disponível em:< https://covid19.who. int/table > Acesso em: set 2020 .

WHO World Health Organization. Report of the WHO-China Joint Mission on Coronavirus Disease 2019 (COVID-19) Geneva, Switzerland, 2020c.

WHO - World Health Organization. Home care for patients with COVID-19 presenting with mild symptoms and management of their contacts, 2020d. Disponível em: <https:// www.who.int/publications-detail/home-care-for-patients-with-suspected-novel-coronavirus-(ncov)-infection-presenting-with-mild-symptoms-and-management-of-contacts> Acesso em: maio 2020.

ZHENG, S. et al. Recommendations and guidance for providing pharmaceutical care services during COVID-19 pandemic: A China perspective. Research in Social and Administrative Pharmacy, v.S1551-7411, n.20, p.30284-9, mar. 2020. 